\title{
Using the Perceptions of Chemical Engineering Students and Graduates to Develop Employability Skills
}

\author{
Ashleigh J. Fletcher*, Abdul Wadood A. Sharif and Mark D. Haw \\ Department of Chemical and Process Engineering, University of Strathclyde, Glasgow, G1 1XJ \\ ashleigh.fletcher@strath.ac.uk
}

*Tel.: +441415482431

\begin{abstract}
Recent years have seen increased global industry sector demand for chemical engineers, subsequent growth of Chemical Engineering (CE) degrees, producing additional qualified graduates. The Confederation of Business Industry have regularly indicated that employers are dissatisfied with skills sets offered by graduates; a 2004 World Chemical Engineering Council (WCEC) survey of experienced and newly employed chemical engineers' perceptions of their own work skills indicated highest importance for general transferrable skills, with technical knowledge ranked considerably lower. A decade later, we investigate whether chemical engineers, both employed and in education, have similar skills perceptions, by surveying CE undergraduates in penultimate and final years of study, and CE alumni employed in CE roles; all from the University of Strathclyde. Again, transferrable skills were perceived as most important to respondents; as undergraduates gained industrial experience, a shift in perceived relative importance of technical knowledge occurred, again similar to the WCEC survey, otherwise, alumni and students had similar opinions regarding perceived degree of learning of various skills. Alumni were more critical of the quality of education with regards to management and transferrable skills, while female participants perceived business skills as undertaught, feeling considerably overexposed to the potential of research compared to male colleagues. Focus groups showed that male undergraduates valued 'technical knowledge' and 'communicating professionally'; by contrast, female graduates highlighted 'initiative' and 'business skills'. Consequently, training sessions were developed, focussing on transferable skills identified as important by all groups, to be delivered during academic year inductions, aligning skills to year curricula.
\end{abstract}

Keywords: Transferable skills; Employability; Curricula alignment; Skills training; Personal development; professional outcomes 


\section{Introduction}

Chemical Engineering (CE) is a versatile discipline, both in education and employment. The taught curriculum is varied, offering problem solving, design, control, management, materials science, safety, economics and environmental impact, in tandem with CE fundamentals, which all prepare students for a range of roles within industry and research. This accrual of knowledge, in itself, is only part of the educational process, which ideally also sees students develop key transferable skills required within chemical and engineering industries. Often, such 'soft' skills are latent within the curriculum with the consequence that participants may not immediately perceive the degree of learning or of opportunity to learn. Hence, students are encouraged to engage with professional development activities to reflect on their own progress. However, it is also essential for staff, as educators, to similarly understand when and how such transferable skills are being developed.

In the UK alone, there has been an overwhelming increase in interest in CE degrees. Successively from 2000 to 2014, CE degree intake has seen growth. In 2013, there was a record 2,790 enrolments on CE courses across the UK compared to 1,820 enrolments in 2010 [1]. With this growth in student recruitment, it is vital that the $\mathrm{CE}$ student cohort is provided with a high quality education, fit for industrial standards. As with many other disciplines, a professional body will often accredit university courses for quality assurance but such accreditation alone may not perfectly capture the success or otherwise of 'latent' skills development. This paper focusses on understanding the perceived skills development and shortages within the recent CE degree programme delivery at the University of Strathclyde (UoS). By canvassing recent undergraduates and Strathclyde alumni, the aim is to understand those skills perceived to be under taught within the current programme and how these may be further developed within the current curriculum.

\section{Background}

\subsection{Institute of Chemical Engineers (IChemE) Course accreditation}

The global professional body of membership for chemical engineers is the Institution of Chemical Engineers (IChemE), who provide accreditation of university degree courses and company training schemes, and award qualifying members with chartered status (Figure 1) [2]. Other engineering accrediting bodies take a similar role to the IChemE such as the Accreditation Board for Engineering and Technology (ABET) and Engineers Australia (EA) for chemical engineering programs within their respective countries and internationally too. The IChemE aim to ensure that the CE workforce remains skilled and, as an accrediting body, bring their experience of best global practice when assessing institutions and awarding chartership to members [2]. Accreditation has the benefit of worldwide recognition for $\mathrm{CE}$ courses and provides a comprehensive benchmark with which $\mathrm{CE}$ departments and courses are evaluated. Accreditation also benefits students, with a structured route to chartered status once employed and satisfying the experiential requirements for chartership. Consequently, documentation is available from IChemE [2] that provides a thorough framework to which all participating institutions must adhere to if they wish to seek accreditation, wherein IChemE adopt an approach based on learning outcomes (LOs) as opposed to being content-driven, which has 
been the general paradigm shift across engineering education [3-5]. LOs focus on the student; highlighting the expected skill or capability, but not necessarily the method or content with which it must be achieved. As a result, this gives academia greater flexibility in teaching, however, it can be hard to explain the exact subset of skills developed in cohorts and assessing some outcomes can prove difficult. Furthermore without explicit knowledge of LOs, learners may not be aware of the aims of, or meet the requirements to achieve, these LOs [3].

Nevertheless, accrediting bodies such as the IChemE, ABET and EA, have adopted and outlined outcomes in their respective guidelines. Some of the similar outcomes found in available documentation $[2,6,7]$ have been highlighted in Table 1.

\subsection{University of Strathclyde Chemical Engineering Department}

In line with the global trend, the University of Strathclyde (UoS) has seen significantly increased student enrolments in their undergraduate CE degrees, with a doubling of student intake over the past ten years (Figure 2). Strathclyde's CE degrees have long been accredited and the department has adopted a LO approach to teaching, with key LOs split into three broad areas of university education, technical knowledge and understanding, practical experience and transferable skills. As expected for an accredited programme there is coherency between IChemE's LOs and those set by UoS Chemical and process engineering (CPE) department. Technical knowledge and understanding are fundamental to the discipline of $\mathrm{CE}$, summarised in the current UoS degree programme as 'a good understanding of chemical engineering principles', 'an awareness of the responsibilities of professional engineers for safety and the environment' and 'a good understanding of the technologies and methods which underpin the design, operation and management of processes which are safe and have minimum impact on the environment. Practical experiences are provided by 'laboratory and practical work and a knowledge of best practice in the collection, analysis and presentation of experimental data' and 'generic IT skills such as word processing, spread-sheeting and subjectspecific IT skills such as computational, design and simulation packages'. Transferable skills are those required in all professions and roles, such as 'written and oral communication, project work and team work' and 'experience in a range of analytical and problem solving skills'. The curriculum is structured so as to provide good skills development for future employment, in alignment with the policies of IChemE and, ideally, congruent with prospective employers' expectations.

\section{Employers' and Employees' perceptions}

The Confederation of British Industry ( $\mathrm{CBI}$ ) conducts an annual education and skills survey. The 2011, 2012 and 2013 surveys collated the views of 566, 542 and 294 employers, respectively, consisting of either the managing director, chief executive, chairman or human resource director and representing combined workforces of $\sim 2.2 \mathrm{~m}, \sim 1.6 \mathrm{~m}$ and $\sim 1.24 \mathrm{~m}$ employees, respectively [8-10]. Approximately $30 \%$ of respondents represent the engineering, manufacturing, energy and water sectors. All employers were asked to rate their satisfaction with graduates' employability skills as either 'very satisfied', 'satisfied' or 'not satisfied', ranking seven key employability skills identified by $\mathrm{CBI}$ as valued by employers; the awarded ranks of dissatisfaction amongst employers are shown in Table 2. It is notable that five of the seven key graduate employability skills have increasing levels of 
dissatisfaction amongst employers, while graduates' relevant work experience also scores highly in terms of employer dissatisfaction.

In 2004, the World Chemical Engineering Council (WCEC) surveyed 2,158 participants from 63 countries, with varying employment spells, to investigate 'how does chemical engineering education meet the requirements of employment?[11], ranking 26 preselected skills on a Likert scale (1: very low to 5 : very high) according to the respondents perceived views of the quality of their education and the relevance of each skill to their work. Table 3 shows the average response of the various skills in order of perceived importance to work and their rank with respect to the perceived deficit in skill acquisition.

One critique of using the average deviation to rank skills is that participants may have been comparative rather than subjective in their evaluation of each skill, using other skills as comparators and skewing the expected evaluation of educational quality and work importance; this is refuted by the authors' validation that both of the perceptions considered in determining the deviation represent the changing views of work and education priorities. An interesting result of this analysis is that the average deviation rank assigned to 'apply knowledge and basic CE fundamentals' is 25th out of 26, compared to the work ranking of $14^{\text {th }}$; being one of only two skills from the survey to exceed the perceived employment requirement from the education perspective, indicating that the IChemE's LO for students to be knowledgeable in 'essential facts, concept, theories and principles of chemical engineering and its underpinning mathematics and sciences' has not only been met, but exceeded. By contrast, many of the skills identified by the survey to be highly important for employment, such as ability to solve problems, ability to work effectively in a team and self-learning abilities demonstrate a competency gap (a negative average deviation), which indicates that educational institutions are not yet addressing the need to develop these skills in their graduates to an appropriate level.

More recently, studies have shown that the WCEC survey results can be confirmed at national levels. An Australian study, conducted by Male et al. [12], found that communication, teamwork, selfmanagement and creativity/problem-solving competencies were amongst the most important competencies amongst practicing engineers, whereas "applying technical theory" was rated lowest. Similarly, Passow's longitudinal study of engineering graduates from an American Midwestern University [13] highlighted a comparable top tier of important competencies which were consistent across seven administrations of an annual survey.

Grant and Dickson [14] have also reviewed the employment skills, including a thorough investigation of a range of accreditation guides, including the IChemE, and associated bodies for graduate recruitment; their resulting classification of the main transferable skills for employment are summarised as:

1. Good at communicating in a variety of forms (written, oral and so on)

2. Able to work well in teams

3. Able to solve problems (pro-actively and with initiative)

4. Numerate and IT literate

5. Able to manage themselves and continue to learn 
which align with the 6 skills identified as most important in employment by the WCEC [11], and in line with IChemE's LOs that graduates must possess skills such as communication, time management, team working, inter-personal, effective use of IT including information retrieval [considered] valuable in a wide range of situations [2]. Agreement also exists between the WCEC survey results [11] and the $\mathrm{CBI}$ reports [8-10], with skills perceived as under taught in universities by current employees similar to those towards which employers have expressed dissatisfaction, most notably business and management skills with significant differences in expected level and resultant deficiencies suggesting measures are required to promote these skills. Thus, there is significant evidence that the most important skills for work are those that are typically considered transferable, and significant deficiencies exist for some skills, which are recognised by both employers and employees.

\section{Framework and methodology}

\subsection{Study objectives}

This study aims to assess the views of chemical engineers, who study or have studied at the University of Strathclyde, using an online questionnaire to gain insight into individuals' views on personal employability both pre-and post-graduation.

\subsection{Methodology}

\section{Evaluation of skills and abilities by questionnaire}

A questionnaire on personal employability was developed to gain quantitative insight into the attitudes of participants, allowing a large sample size for statistical consideration, hence, representation of the perceptions of the full cohort. The questionnaire was distributed online to increase accessibility for participants, providing a spreadsheet of data and responses on completion. To eliminate bias in the collected results data was obtained from all available demographics, including penultimate and final year students, recent graduates or alumni (i.e. within 2 years of graduation), and part-time distance learning students; this crucially provides a representation of the changing attitudes that experience brings to a chemical engineer's views about their work and education. The questionnaire requested:

- demographic information: current educational/employment status, method of course delivery (FT/PT), gender, age, year of study (if applicable) and degree classification,

- career experience and/or interests: type of experience (summer placement, current employment etc.), area of experience, area of interests and offer for graduate employment

- comparison of perceived skills in employment with quality of education and teaching methods: utilising the generic skills/abilities identified by the WCEC (Table 3) [11], excepting 'knowledge of methods for total quality management' and 'knowledge of marketing principles', which were deemed less relevant to chemical engineers.

For the skills comparison, participants rated each skill on a 5-point Likert scale, firstly with respect to how well their education enabled development of the skills and, secondly, with respect to how important the skills were in their current or future employment. It is important to note that all ratings are based on individual perceptions; in the case of those with no work experience, they reflected on what they expected work life would entail. Conversely, it was assumed that graduates had an 
accurate memory of their education and that the general syllabus was mostly unchanged. Participants were also asked to rate themselves or their perceptions of future requirements, in the 5 key areas identified by Grant and Dickson [14], on the same 5-point Likert scale. Finally, participants were asked to rate various modes of teaching, and to identify modules that were particularly beneficial in developing the skills mentioned in the questionnaire. An open response textbox allowed participants to comment on how prepared they were/are for employment and how their preparedness could have been/can be improved by the CE department.

The questions employing a Likert scale were analysed by determining the arithmetic mean or average, $\bar{x}$, from a population of $n$ samples, where $x_{i}$ is the value of sample $i$ :

$$
\bar{x}=\frac{1}{n} \sum_{i=1}^{n} x_{i}
$$

Likert scale questions are a form of ordinal measurement, i.e. there is no assurance that a linear relationship exists between 'Agree Strongly (5)' to 'Agree (4)', hence, an average of 4.6 does not necessarily indicate that the result is closer to 'Agree Strongly (5)'. The misuse of Likert scale averages have been reported in the literature [15], where it has instead been recommended to use the most frequent response i.e. the mode; however, using the average in this study is justified as it is only used as a means of comparison to similar data, not as a discrete result. This technique was also adopted in the WCEC analysis [11].

Average skills deviation, $\overline{\Delta_{s}}$, was calculated as the difference between $\overline{x_{e}}$, the average education response, and $\overline{x_{w}}$, the average work response:

$$
\overline{\Delta_{s}}=\overline{x_{e}}-\overline{x_{w}}
$$

Hence, a negative skills deviation indicates an under-taught skill, whereas a positive skill deviation suggests it is over-taught. This deviation can also be thought of as a quantitative representation of the perceived degree of learning.

\section{Quantitative results and discussion}

\section{Demographic analysis}

The demographic composition of the total of 94 participants is shown in Figure 3. There is a clear gender imbalance; however, the numbers are a fair representation of the general global situation for higher educational engineering courses [16]. The majority of respondents were full-time students. There was insufficient data to provide statistical evidence for the population of part-time students but the group was incorporated to provide breadth to the study [17] and include general comments made by this group. The majority of the participants had industrial experience, validating the data with regards to the aims of this study, and providing a comparison between the expectations of chemical engineers pre- and post-industrial experience, and within graduate employment. 'Experienced' participants comprised those in chemical engineering employment, as well as students who had undertaken internships or summer vacation placements in an industrial setting. Out of the 22 Alumni who responded, all were in employment bar one who had no experience. The participating students 
and alumni represented $79 \%$ and $12 \%$ of their respective target populations. The number of alumni who participated was the most significant limitation, however, the responses gathered were in agreement with other global and national studies discussed below [11-13]. The age distribution (Figure 4) was centred around 22 years of age, indicative of those approaching graduation and recent graduates; respondents above the age of 30 represented the majority of part-time students.

The majority of the participants' experience lay in the oil and gas, chemical process, pharmaceutical and petrochemical sectors (Figure 5); therefore, the results from experienced participants are particularly relevant to these industrial fields.

\section{Full-time students' skills analysis}

The results obtained from the questionnaire showed full-time students rated an appreciation of the potential of research most highly in terms of perceived degree of learning, which was also the most recurring skill to be perceived as over-taught (i.e. the perceived ability level provided by education was greater than the perceived need in working practice), see Figure 6 . This may possibly be an indication of over-exposure to the potential of research, as a result of the background of the teaching staff involved (many lecturers are also researchers), it is also possible that opportunities for students to experience research via summer vacation research placements and final-year research placements increases students' awareness of research. Contrastingly, part-time students were the only demographic to evaluate the skill as under-taught, which may be a consequence of the distance learning nature of these degrees where students, often in full-time employment, do not have the option to undertake research placements or be aware of lecturers' roles as researchers. Other skills considered well taught by full-time students included gathering and analysing information, systematic approach to design and self-learning abilities, agreeing with several identified skills from the previous review by Grant and Dickson [14]. The high evaluation rate of such skills may be explained by considering the demographic itself: full-time students are comprised of penultimate and final year students, at the time of delivery of the questionnaire, penultimate year students were progressing through the group design project and final year students were undertaking either research projects or industrial placements. Furthermore, many classes throughout the CE degree require independent research and learning on certain subjects, culminating in semester-long projects.

The relatively poorest taught skill for full-times students was foreign language knowledge, as seen in Figure 7. As part of the degree programme, participants were offered an elective in language classes in the first year, although the results indicate that this is not considered adequate by the majority of students. The more experienced alumni, however, still rate the foreign languages as under-taught but evaluate it less critically than full-time students (see below). A third of the final year cohort participated in a university exchange program at the time of the survey, which may have influenced the strong importance of foreign language skills. Other perceived poorly taught skills include interdisciplinary approach, understanding cultural diversity and ethical responsibilities, even though the latter is taught together with sustainability and economics in the third year of the undergraduate course. This highlights the abstract and situational importance of ethical issues which can prove challenging to teach. Amongst all demographics, the most widespread under-taught skill is business-orientated 
thinking. Not only is this rated poorly amongst future and current employees but it is the area that employers identify as the most unsatisfactory in graduates [10].

\section{Part-time students' skills analysis}

The least statistically accurate demographic, part-time students, had the most contrasting view with their full-time counterparts and alumni, returning the most favourable views regarding the course, with 6 skills over-taught and 1 ideally taught (project management methods). Unsurprisingly, the over taught skills included self-learning ability; due to the nature of distance learning, part-time students are required to take a more proactive approach to their learning. Other well-taught skills were similar to the alumni: technical knowledge and research appreciation were over-taught, the former being the focus of distance learning (Figure 8).

The poorest taught subjects according to part-time students (Figure 9) included working effectively as a team member, being a leader and communicating effectively; these are the most difficult skills to develop via distance learning as participants are often in different time-zones, there are limited faceto-face meetings and most conversations are conducted using Virtual Learning Environment (VLE) forums. Furthermore, this cohort represents the distance-learning community, composed of a range of international and home students; communication can be difficult with students from different cultures and countries, or individuals whose first language may not be English.

\section{Alumni's skills analysis}

Alumni indicated that knowledge of core $C E$ is over-taught, an expected result as the majority of the degree focusses on fundamentals of CE such as basic principles, thermodynamics, fluid flow, heat transfer, reactors, process analysis and separations. Interestingly, full-time students rated this ability poorly with a deviation of -0.469 , indicating a perception of insufficient CE knowledge expected for professional work. There is a clear and distinct change in attitude as graduates gain more experience indicating that the CE knowledge is more than sufficient for graduates to develop in their future roles. Similarly, systematic approach to process design is near the perceived ideal for employment, along with self-learning abilities. Identification, formulation and solving of problems are rated highly as key skills for employment, as mentioned previously [14], and this is an area that employers have recognised as weak amongst graduates [10]; CE alumni rate this with a small deviation of -0.182 (Figure 10), demonstrating a potential closure of this gap.

Generally, alumni were concerned (Figure 11) with business related skills such as project management methods, management skills and business-orientated thinking. Although project management is a taught class, at the time of the study it is delivered in the second year of the degree course and is not explicitly revisited in later years. The CE department have recognised this and plan to move the module to run alongside the penultimate year $\mathrm{CE}$ design project in the form of e-learning; otherwise, there are no business or management classes offered in the undergraduate course. The UoS does offer many free, bookable classes on self-management, effective time management and leadership; but these are not well publicised and often conflict with scheduled class times. 


\section{Full-time students and alumni comparison}

Generally, students and alumni have similar views on the perceived degree of learning for all skills, except knowledge of core $C E$, where students perceive it as more relevant for employment than it actually is, as observed by the alumni's positive degree of learning result (Figure 11). As mentioned earlier, it is necessary to be aware that there is a significant bias exhibited by both groups. The fulltime students have an 'accurate' perception of education as they were undertaking their degree at the time of canvassing; hence, full-time students are required to project forward their views and anticipate what skills employment will necessitate. On the other hand, alumni have an 'accurate' view of the skills required for their employment, yet some time has passed since graduating from their respective degrees, and employment experience will most likely have altered their views of education. It is also important to note that the content of the degree programme has changed over the years and alumni will have a different perception of what is taught. Although both groups carry a bias, there are some coherent views, such as competence in IT and critical thinking (Figure 12).

The comparison between alumni and full-time students' responses to rating skills, in terms of importance to employment, is shown in Figure 13. Those skills considerably exceeding the average difference between the two groups are highlighted with an ' $X$ '. Students underestimate skills such as appreciation of an interdisciplinary approach, project management methods and business-orientated thinking whilst overestimating the importance of certain skills: knowledge of core CE and ethical responsibilities. This indicates a general change in graduate perspective once they have gained experience of work life: from one concerned with technical CE knowledge to one focussed on business methods and success. Furthermore, the ranking of the skills importance by alumni reflect studies conducted by others globally and nationally. Passow's longitudinal study on ABET competencies found a statistically-significant top tier of competencies comprised of teamwork, communication, data analysis and problem solving [13]. Male's Australian study similarly highlighted communication related skills; working in team; managing self; solving problems amongst the top ranked skills [12]. Both these studies provide support for the rating of these skills given by alumni.

Both demographics do, however, agree upon the significance of the five most important skills for employment mentioned previously. Of particular interest is that both groups identified the two most important skills for employment to be the same: effective communication and effective teamwork, indicating that these skills are of high value, yet these skills are perceived as under-taught by both groups. This should be considered carefully as lack of confidence in a skill may manifest as perceived under-teaching, which may contribute to employer views expressed in studies such as those conducted by the CBI.

\section{Experienced and non-experienced comparison}

Industrially experienced and non-experienced participants had similar views on most skills assessed in the questionnaire but there were some significant differences. Appreciation of the potential of research was perceived to be considerably over-taught by those with experience, whereas nonexperienced participants considered it a skill slightly under-taught; this may be a consequence of nonexperienced individuals who do have research experience but lack exposure to industrial experience 
(Figure 14). Despite their comparable curricula while at University, non-experienced participants also rated foreign languages as considerably more under-taught (deviation -1.103) than experienced participants (deviation -0.631), perhaps indicating greater importance of foreign languages in nonindustry related careers, such as academic research. However, it is possible that some nonexperienced participants who wish to pursue an industrial career may overestimate the importance of foreign languages. Both groups recognise the importance of foreign language knowledge, as both research and industry are international career options. Competence in IT is an area that industrially experienced participants recognise as considerably under-taught (deviation -0.662) in comparison to those with no experience (deviation -0.310); this is more of a complaint regarding employer specific software that graduates encounter, as reflected in the individual comments. This is a difficult issue for educators to address as there are many different software used by employers. It perhaps indicates the need for specific IT training led by employers that builds on core IT competence gained at University.

\section{Gender analysis}

Female and male participants had substantially different views regarding many skills; most notably business orientated thinking and appreciation of the potential of research (Figure 15). Females evaluate business orientated thinking more critically than males and identify the potential of research as more over-taught than males. It is interesting to consider this result in the context of female career preferences, with studies indicating that the majority of women studying engineering go on to nonengineering employment upon graduation $[16,18]$ and that female students are significantly less likely to believe that they will remain in engineering-related fields than their male counterparts [19]. The result of our survey may be evidence of a greater interest in female respondents of pursuing business as opposed to technical careers, whether within or outside the sector. Women evaluated self-learning ability, need for lifelong learning and gathering information closer to the ideal teaching for employment but felt slightly less confident with regards to competence in $I T$ than males, and much less confident in effective communication. This may be due to the gender imbalance in engineering sectors, which may result in lower confidence for females when communicating with peers [20].

\section{Teaching methods analysis}

Full-time students and alumni recommended lectures with tutorial support as a teaching method, closely followed by group-orientated projects, the importance of which is emphasised in the CE design project, which allows student to develop a number of skills and provide experience of independent research (Figure 16). Conversely, part-time students preferred video lectures with tutorial support, as this is the most accessible method distance learners, who criticised group-orientated projects, probably due to the difficult nature of remotely managing a group.

\section{Experience and employment analysis}

At the time of delivery of the questionnaire, 18 student participants (51\%) with prior experience had received graduate job offers, compared with only 2 non-experienced respondents $(7 \%)$. This key 
finding indicates the value that employers place on previous experience; indeed the CBI have consistently reported the high dissatisfaction of employers with regards to this attribute [10].

\section{Addressing the issues}

The survey results suggest that, on average, those with experience felt that their technical knowledge surpassed the requirement for employment, while transferable skills and management-related subjects were generally lacking. Although learning outcomes are beneficial to learning and teaching, students may not be completely aware of which skills they have developed during their time at university, if not explicitly stated. This is of particular concern with embedded learning outcomes for transferable skills, which are often additional to the main content of the course but allow students to develop certain skills or awareness. These embedded learning outcomes are utilized in the course as is documented in the UoS CE undergraduate handbook. Fitzpatrick et al. [3] found that students taught using explicit reference to the class LOs expressed confidence in understanding the LOs based on students' prior and post teaching perceptions. More importantly, almost all students found the session, which communicated the LOs, to be useful. Similarly, Felder's work on the explication of learning outcomes highlights the importance for academic staff to have established clear and specific LOs [4, 5]. For these reasons, it was recommended that academic staff should incorporate a proactive approach and introduce classes with a verbal or written explanation of the various learning outcomes associated with the module; upon closing a class the learning outcomes should be restated, to allow students to reflect on the material covered. Due to the low evaluation of most transferable skills, it was recommended that classes should be introduced to cover various skills that are relevant and useful to students, both during their time at university and once they enter their chosen career: industrial, academic or otherwise.

\subsection{Potential delivery constraints for delivering transferable skills}

Degree flexibility - Currently, the degree offers very little flexibility for additional modules to be introduced on top of the 120 credits per year workload, which corresponds to 1200 hours of student learning, including lectures, assessment work and exams. As mentioned previously the department is required to meet certain learning outcomes for accreditation purposes and many core classes are integral to this. One solution might be to replace an already existing Integrated Masters 5 th year module with content pertaining to professional skills development. Such modules focus on specific subjects and are required to be of sufficient depth for accreditation; however, students have freedom of choice in class selection and there is some scope for variety within accreditation expectations from advanced level classes. Unfortunately, to address the concerns raised by questionnaire participants, an introductory class timed at the start of semester was more preferable, which would not be favourable for accreditation. An alternative was to deliver an extra-curricular lecture series, however, this required additional teaching time for staff and would potentially result in poor student participation.

Teaching Staff - Staff availability is key to delivery of any module; however, lecturers often have many roles (as researchers, supervisors and academic advisors etc.). Another valuable resource for teaching is postgraduate researchers, and following publication of the Robert's Review in 2002 there 
has been increased focus over the well-rounded capabilities of researchers [21]. As a result the University of Strathclyde have adopted a Researcher Development Programme (RDP), which requires $\mathrm{PhD}$ students to accrue 60 credits during their research degree towards a Postgraduate Certificate (PGCert). Students are required to submit evidence of the development of a range of skills, e.g. supervising and teaching junior students. Involving PhD students in the teaching of this module both provides credit-bearing experience for $\mathrm{PhD}$ students while removing some demand on otherwise preoccuiped lecturers. However, lecturers still need to design classes and assessments for delivery by PhD students and it is important to recognise that not all PhD students and lecturers will have industrial 'work' experience.

Assessment - Evaluation can provide documented evidence that a student has demonstrated attainment of specified learning outcomes and can take a variety of forms; formal examination, assessments, class tests and group projects. Assessment has been shown to increase class attendance [22]. Continuous assessment is beneficial to both student and teacher as it provides valuable feedback to both, allowing the former to improve upon weaker areas and the latter to focus on identified failings. On the other hand, assessment can be time-intensive, hence, the proposed class should require no formal assessment, which is not an issue if the class is not tied to a core module. Instead it is suggested that students who attend will be awarded a 'skills award' that will be presented on their academic transcript, thus ensuring attendance. Additional to this an alternative option, allowing immediate feedback and assessment of the general topics of the classes, would be personal response systems (PRS); If coupled with meaningful questions and preparation these could provide significant feedback for class improvement.

Class Sizes - Over the last few decades, universities have undergone a process of 'massification' whereby student enrolment and class sizes have increased dramatically [23]. CE continues to attract increasing numbers of students and class sizes have increased rapidly, which presents a potential issue with regards to student performance. On average, "larger classes reduce students' achievement as measured by test scores" $[23,24]$ albeit the magnitude of the inverse relationship between large class size and student final mark in a higher education setting is significantly smaller than other tiers of education [23]. Nevertheless, it is beneficial to consider online virtual learning environments (VLE) to deliver the material, increasing accessibility for all students, including distance learning cohorts. Due to the ever increasing CE cohorts, it is wise to consider sustainable changes when implementing classes.

Delivery Proposal - To minimise impact on staff workload, it was recommended that $\mathrm{PhD}$ students deliver the material, allowing credit accrual for the RDP; such sessions would be run as part of the yearly induction program for all student year groups. The proposal would not add significantly to teaching hours and, at the time of writing, was a scheduled part of students' timetables. As the yearly inductions incorporate the full cohort, the class sizes are already accommodated for the complete year group. There is a relatively high attendance at early years' induction events, with lower attendance in later years, most likely due to the brief and repetitive nature of previous yearly inductions; students are informed of the classes they will undertake and given a general welcome 
followed by a careers talk. Introducing lectures on practical skills may improve attendance, and by delivering skills development at the start of the semester, the skills covered can be matched to the demands of the upcoming academic year and advertised as such e.g. the 4th years induction covers running effective meetings in preparation for the group design projects. Meaningful feedback and assessment of the session could be obtained by paper surveys, show of hands or even web-based feedback applications that can be run on smart phones such as Socrative[25], however, the latter would require good wi-fi availability/assurance that students were in possession of smart devices.

\subsection{Practical Suggestions for delivering transferable skills}

Induction skills classes - Transferable skills were selected for their relevance and practicality to the degree course and a variety of job roles. These are outlined below with justification of relevance, cohort delivery recommendations and resources used to develop materials.

\section{Steve Jobs or Bill Gates? How to Develop and Deliver Excellent Presentations serves to} improve student perception of the degree of learning of effective communication, rated both an important and poorly skill by most demographics. The importance and lack of exposure to presentations were mentioned specifically by some participants of the questionnaire, with several noting their preference to 'give students a chance to practice presentations' and others, the belief that they 'lack presentation skills in comparison to others from different universities'. Furthermore, this is an important skill for students who go on to pursue post-doctoral degrees, with group presentations a regular occurrence. Reviewing the curriculum, it was found that presentations are required from students in 1st, 2nd and 5th year, hence it was decided that delivering presentation skills material prior to 1st year presentations would be of greatest benefit to students, allowing students to apply the teachings in later years as well. Topics covered include planning, design and delivery, and resources used were Weissman's Presentations in Action [26] and Reynolds' Presentation Zen series [27, 28].

Cramming or Prepared? How to Organise and Manage Your Time was developed to reduce the students' negative perceptions with regards to management skills and self-learning ability, introducing concepts for project management methods. Management is involved in decision making with regards to available resources and time is a resource that every student and employee possesses and uses to achieve a goal - an invaluable skill for students to learn. In 2nd year, students have a significant number of assignments with staggered hand-in dates; importantly, in this year the module Chemical Engineering Practice 1 is introduced, which requires students to participate in several laboratory sessions and submit a detailed report fortnightly over the course of the year. This continues in the following year with the delivery of Chemical Engineering Practice 2. Both modules run over two semesters, requiring individual effort and resolution of conflicting deadlines requiring good organisational skills. This skill is also valuable in later years, particularly 4th and 5th years, as students are required to participate in group and individual projects, respectively - the importance of a proactive approach and good self-management is key for succeeding in complex projects. Areas covered include Eisenhower's time matrix, scheduling, combating procrastination and technological assistance using the Sunday Times' publications: Successful Time Management [29] and Organise Yourself [30] as resources. 
Group or Team? How to Work Effectively as a Team - The importance of teamwork for chemical engineers was recognised by both alumni and students who participated in the questionnaire. The $\mathrm{CBI}$ has also noted this as a key employability skill, with a fifth of employers unatisfied with team working abilities in graduates. Chemical engineers have particular interest in effective teamwork as they often work as part of interdisciplinary teams made up of engineers from various disciplines. It is vital for academic success that students are able to perform well in teams and, likewise, for graduates to do so to achieve business success. Students are exposed to elements of team work in all years, and the most important year for students to be able to perform well in teams is 4 th year as part of the 60-credit design module, a hallmark feature of all accredited CE degrees. During this module students are expected to work together, assign roles, delegate and collectively come to decisions to achieve common goals, which is the essence of team work. Although it was initially considered to deliver the material in the 4th year it was instead considered more beneficial to run the material in 3rd year prior to the introductory course for the 4th year design project; Chemical Engineering Design and Advanced IT. This module gives students a simpler and more constrained primer to 4th year design but with the same element of team work. For this reason students can apply the material initially in the 3 rd year, working to improve their performance in the capstone 4th year group projects. Areas covered include stages of team development, team styles, team roles and methods for team problem solving and decision making, using De Bono's Six Thinking Hats [31], Belbin's Team Roles [32], Effective Teamwork: Practical Lessons from Organisational Research [33] and Team Players and Team Work [34] as resources.

Organised or Time-Wasted? How to Plan and Run Effective Meetings - An important aspect of effective teamwork, communication and management is being able to organise and execute meetings that are time-efficient and address the need for the meeting. Meetings are required for many reasons as part of the undergraduate degree: to update team members on progress, to inform supervisors of progress, to discuss issues, to plan coming events and to make decisions. Similarly, meetings have a vital role to play in employment, however, meetings can often be counter-productive if not planned properly and result in wasted time. Meetings often go hand-in-hand with teamwork, although not exclusively, and require a tailored approach depending on the purpose of the meeting. As a result, meetings are present in every year of the undergraduate degree course and the proposed material may have been delivered in any year but, as undergraduates are presented with the most number of meetings in their 4th year, as part of design, it was recommended that the material on meetings be run in 4th year. Students meet with design supervisors on a weekly basis but are also expected to meet regularly outside these meetings to make decisions, update team members and work together, providing significant practice, while the 5th year research project provides an additional opportunity for improvement. Meeting preparation, types of meetings, key roles in meetings and post-meeting considerations are covered using Barker's How to Manage Meetings [35] and Delehant's Making Meetings Work [36] as resources.

Project management methods and business-orientated thinking accrued high average skills deviations amongst alumni; however, the significant body of published literature associated with these skills indicates that they are unsuitable for short induction classes. Instead, it was recommended that 
implementation of both be embedded within the curriculum. An example of this implementation for business-orientated thinking skills was the explicit and graded division of group design projects to include a conceptual phase which required students to provide a feasibility study and business justification for the proposed design.

\section{Conclusions}

Employers have recognised various shortcomings in graduates, as observed by the Confederation of British Industry. In this study, the views of chemical engineers with regards to employability skills were obtained by means of a survey; transferable skills were deemed most important for employment. In addition to this, management and transferable skills were perceived to be under taught by the participants, hence, the development of these skills was addressed by the introduction of induction skills classes. Taught by PhD students, with instant feedback received via a smart device-based personal response system, the classes focus on presentations, time management, effective teamwork and meetings in alignment with student needs throughout the current degree programme.

\section{Questions raised/further study}

The results also indicate directions worthy of future, more detailed, study. The contrast between male and female perceptions and confidence is clear, and it would be informative to further explore this, especially given current concerns over gender equality of opportunity in engineering and science. The transition of perceptions from students at university to alumni is clear in some cases, such as the perceived importance of, and competence in, core chemical engineering knowledge, and it would be interesting to study, in more detail, how perceptions of confidence in skills develops throughout the university career as well as the impact of skills development on the early years of industrial experience. Graduates do not stop learning once they leave university, and with such a diverse range of activities in the CE sector, further development of skills is of core importance to the industry. Further, work to understand what definitions are associated with various skills such as effective communication and teamwork would prove to be helpful for educators. 


\section{References}

1. UCAS. Universities and Colleges Admissions Service Data Analysis. 2015 05/05/2016];

Available from: http://www.ucas.com/data-analysis.

2. The Institution of Chemical Engineers, A guide for university departments and assessors: Based on learning outcomes, 2012, The Institution of Chemical Engineers,.

3. $\quad$ Fitzpatrick, J.J., E.P. Byrne, and D. Kennedy, Making programme learning outcomes explicit for students of process and chemical engineering. Education for Chemical Engineers, 2009. 4(2): p. 21-28.

4. Felder, R.M., A. Rugarcia, and J.E. Stice, The future of engineering education V. Assessing teaching effectiveness and educational scholarship. Chemical Engineering Education, 2000. 34(3): p. 198-207.

5. $\quad$ Felder, R.M., et al., The future of engineering education II. Teaching methods that work. Chemical Engineering Education, 2000. 34(1): p. 26-39.

6. Australia, E., Engineers Australia policy on accreditation of professional engineering programs. Accreditation Board, Document, 2005(P02): p. 7.

7. Commission, E.A., Criteria for accrediting engineering programs. Accreditation Board for Engineering and Technology Inc, 1999.

8. Confederation of British Industry. Building for Growth: Business Priorities for Education and Skills - Education and Skills Survey 2011 [Online]. 2011 24/03/14]; Available from: http://www.cbi.org.uk/media/1051530/cbi edi education skills survey 2011.pdf

9. Confederation of British Industry. Learning to Grow: What Employers Need from Education and Skills - Education and Skills Survey 2012 [Online]. 2012 24/03/14]; Available from: http://www.cbi.org.uk/media/1514978/cbi education and skills survey 2012.pdf

10. Confederation of British Industry. Changing the Pace - CBI/Pearson Education and Skills Survey 2013 [Online]. 2013 24/03/14]; Available from:

http://www.cbi.org.uk/media/2119176/education and skills survey 2013.pdf

11. World Chemical Engineering Council. Survey:How Does Chemical Engineering Education Meet the Requirements of Employment [Online]. 2004 24/03/2014].

12. Male, S.A., M.B. Bush, and E.S. Chapman, Understanding generic engineering competencies. Australasian Journal of Engineering Education, 2011. 17(3): p. 147-156.

13. Passow, H.J., Which ABET Competencies Do Engineering Graduates Find Most Important in their Work? Journal of Engineering Education, 2012. 101(1): p. 95-118.

14. Grant, C.D. and B.R. Dickson, Personal Skills in Chemical Engineering Graduates: The Development of Skills Within Degree Programmes to Meet the Needs of Employers.

Education for Chemical Engineers, 2006. 1(1): p. 23-29.

15. Jamieson, S., Likert scales: how to (ab) use them. Medical education, 2004. 38(12): p. 12171218.

16. Fouad, N.A. and R. Singh, Stemming the tide: Why women leave engineering. Center for the Study of the Workplace report, University of Wisconsin-Milwaukee, 2011.

17. Lenth, R.V., Some practical guidelines for effective sample size determination. The American Statistician, 2001. 55(3): p. 187-193.

18. Powell, A., A. Dainty, and B. Bagilhole, Gender stereotypes among women engineering and technology students in the UK: lessons from career choice narratives. European Journal of Engineering Education, 2012. 37(6): p. 541-556.

19. Amelink, C.T. and E.G. Creamer, Gender Differences in Elements of the Undergraduate Experience that Influence Satisfaction with the Engineering Major and the Intent to Pursue Engineering as a Career. Journal of Engineering Education, 2010. 99(1): p. 81-92.

20. Merchant, K., How Men And Women Differ: Gender Differences in Communication Styles, Influence Tactics, and Leadership Styles, 2012: CMC Senior Theses. Paper 513.

21. Roberts, G.G., SET for success: the supply of people with science, technology, engineering and mathematics skills: the report of Sir Gareth Roberts' review. 2002.

22. Nyamapfene, A., Does class attendance still matter? engineering education, 2010. 5(1): p. 64-74.

23. Bandiera, O., V. Larcinese, and I. Rasul, Heterogeneous class size effects: New evidence from a panel of university students*. The Economic Journal, 2010. 120(549): p. 1365-1398.

24. Feldman, K.A., Class size and college students' evaluations of teachers and courses: $A$ closer look. Research in Higher Education. 21(1): p. 45-116.

25. MasteryConnect. Socrative (O). [Web Page] [cited 2016 29th April]; Available from: http://www.socrative.com/index.php. 
26. Weissman, J., Presentations in action: 80 memorable presentation lessons from the masters2011: Pearson Education.

27. Reynolds, G., Presentation Zen: Simple ideas on presentation design and delivery2011: New Riders.

28. Reynolds, G., Presentation zen design: simple design principles and techniques to enhance your presentations2013: New Riders.

29. Forsyth, P., Successful time management2013: Kogan Page Publishers.

30. Caunt, J., How to Organize Yourself. Vol. 46. 2013: Kogan Page Publishers.

31. De Bono, E., Six thinking hats1989: Taylor \& Francis.

32. Belbin, R.M., Team roles at work2012: Routledge.

33. West, M.A., Effective teamwork [internet resource] : practical lessons from organizational research, ed. P.D.A. Dawsonera2012, Oxford: Oxford : Wiley-Blackwell.

34. Parker, G.M., Team players and teamwork: New strategies for developing successful collaboration2011: John Wiley \& Sons.

35. Barker, A., How to manage meetings [internet resource], ed. P.D.A. Dawsonera2011, London: London: Kogan Page.

36. Von Frank, V. and A.M. Delehant, Making meetings work: How to get started, get going, and get it done2006: Corwin Press. 


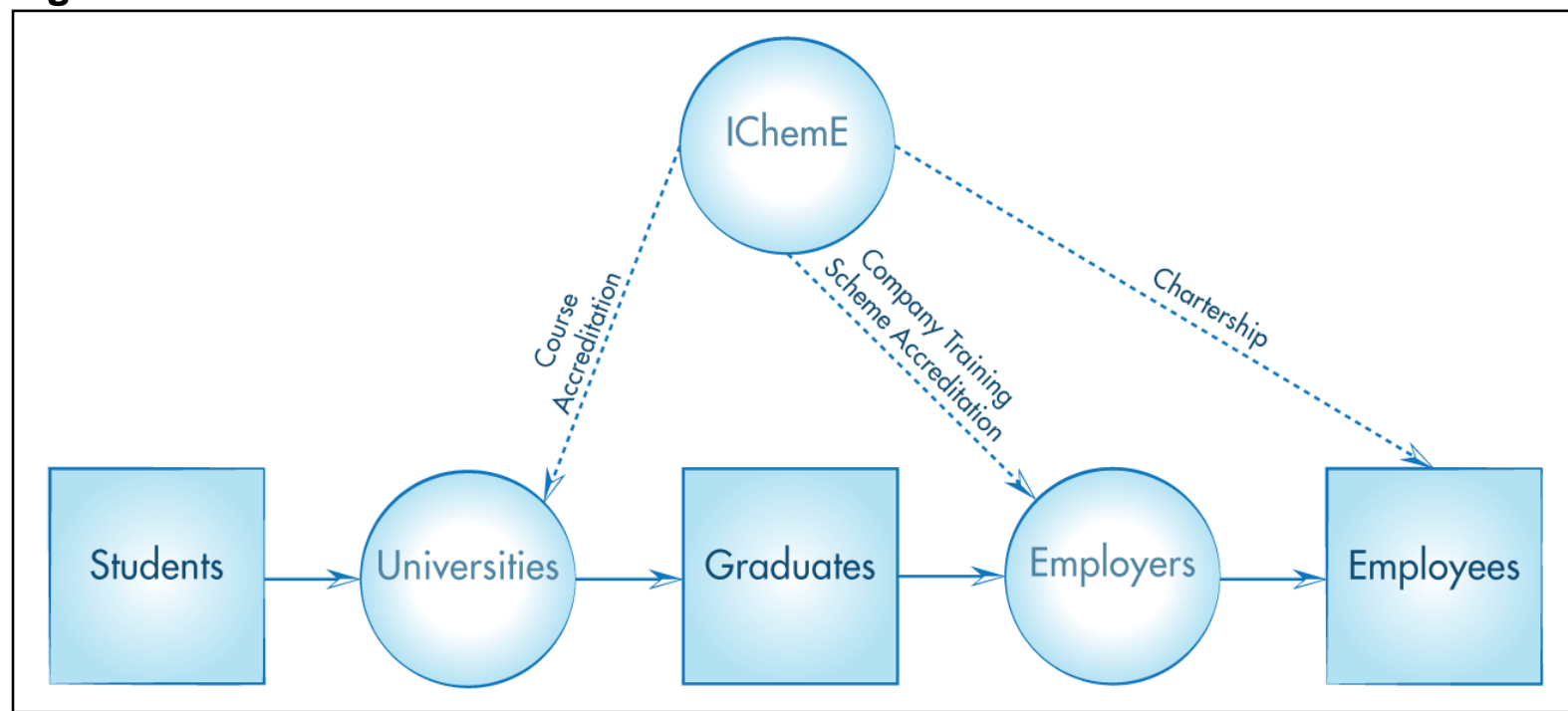

Figure 1 The route from CE student to employee and the various agencies involved.

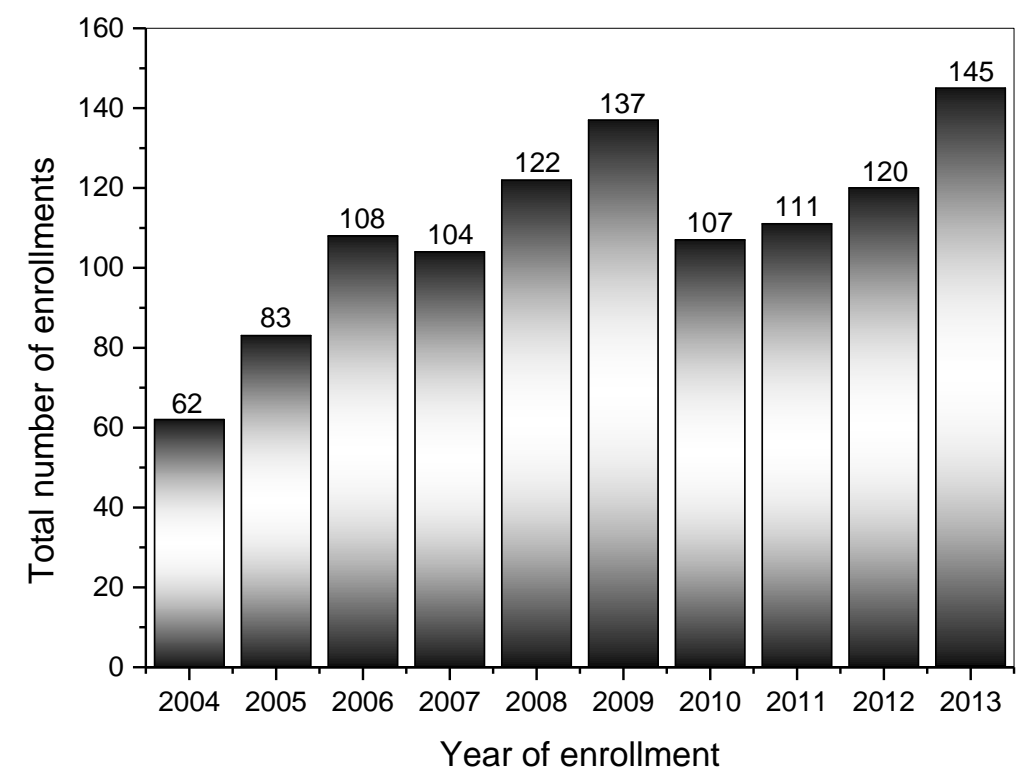

Figure 2 Enrolments to Year 1 degree programmes offered by the Department of Chemical and Process Engineering, University of Strathclyde, from 2004 to 2013

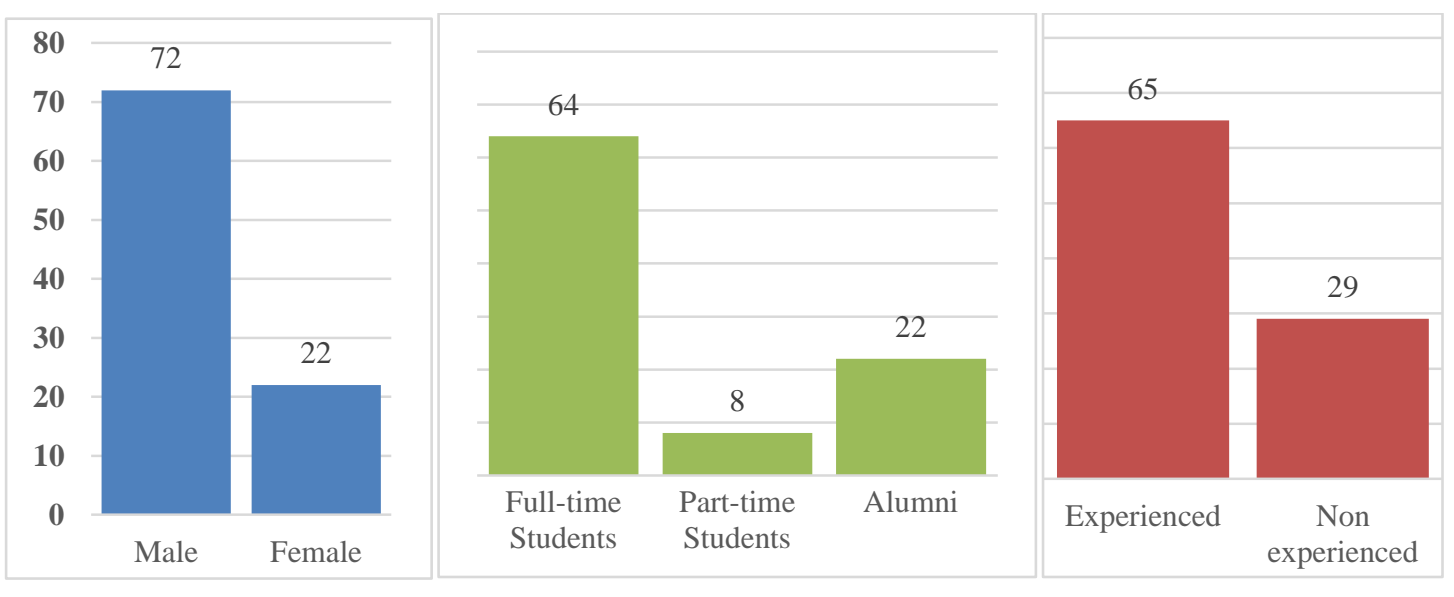


Figure 3 Demographic breakdown of participants canvassed for their perceptions of employability in chemical engineering sectors. Experience refers to either graduate chemical engineering employment or an internship during studies.

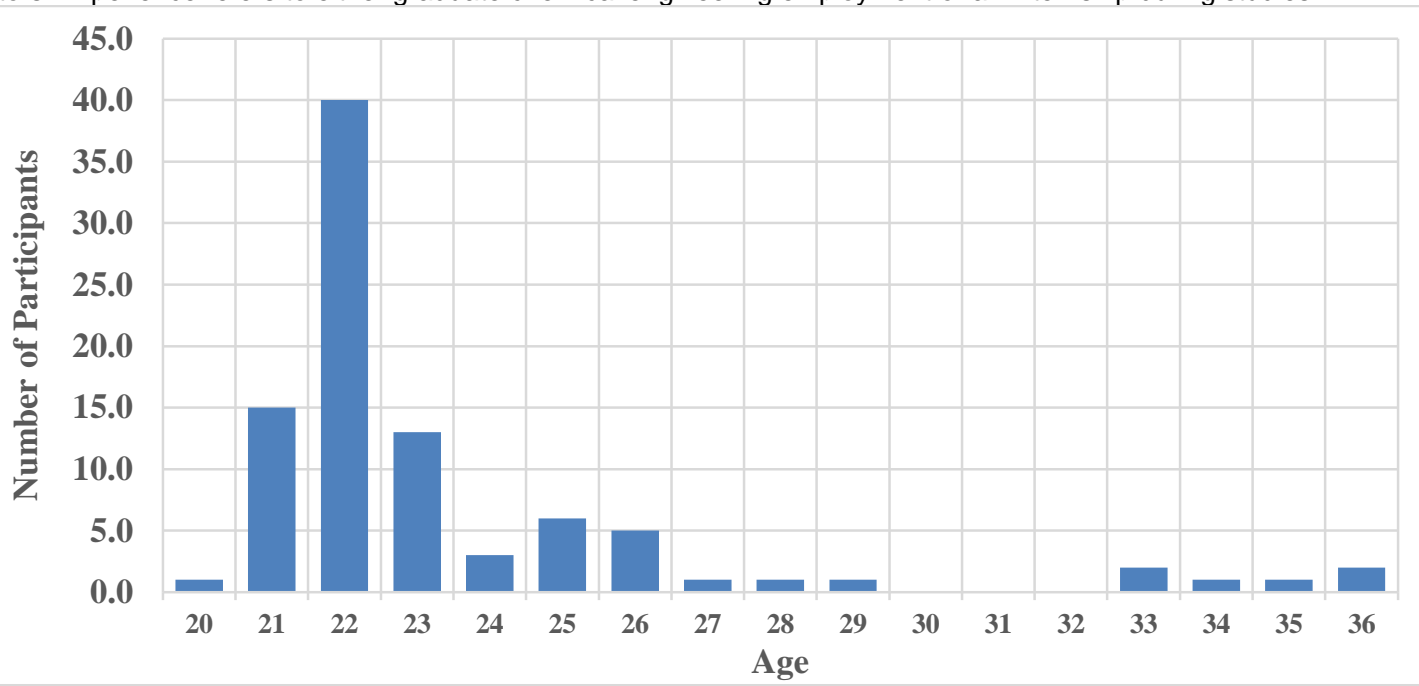

Figure 4 Age distribution of participants canvassed for their perceptions of employability in chemical engineering sectors.

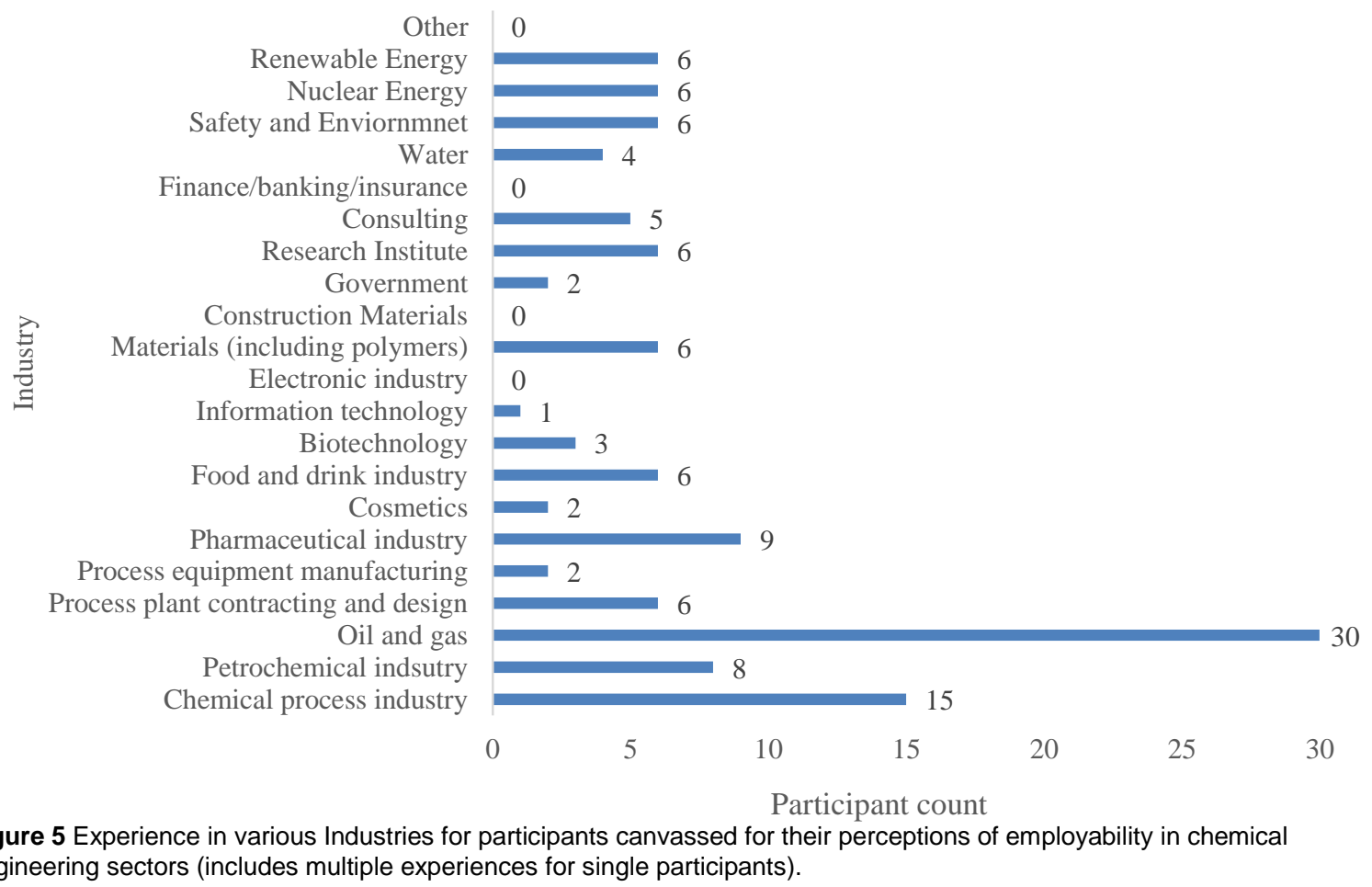




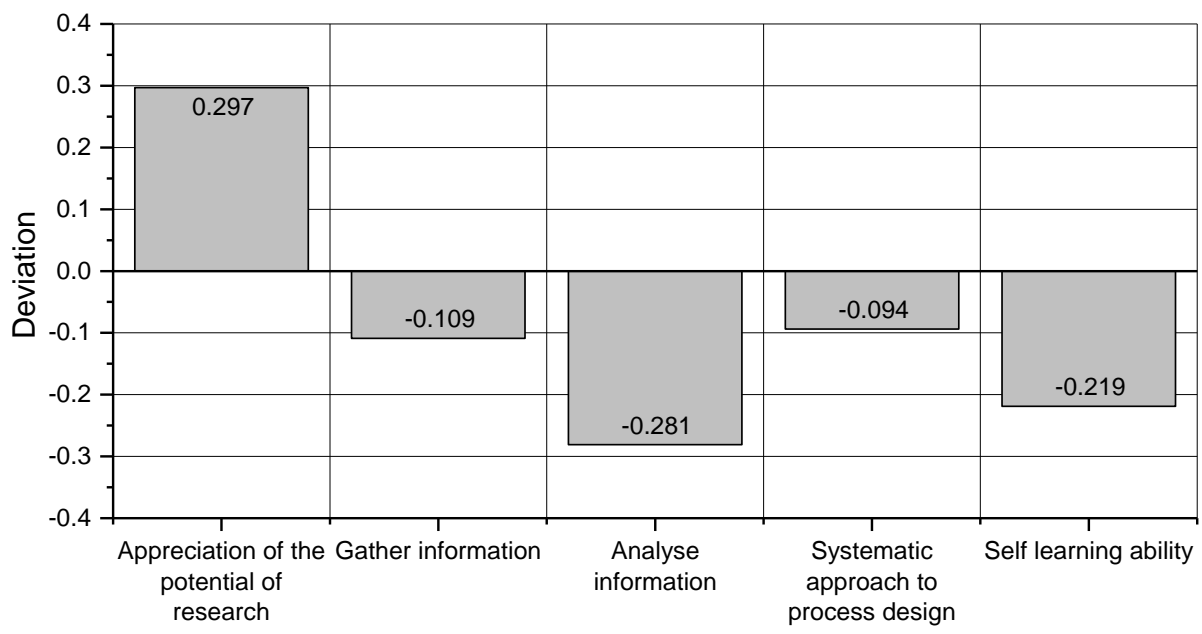

Figure 6 Full-time students' highest rated skills in terms of perceived degree of learning $\left(\overline{\Delta_{s}}\right)$.

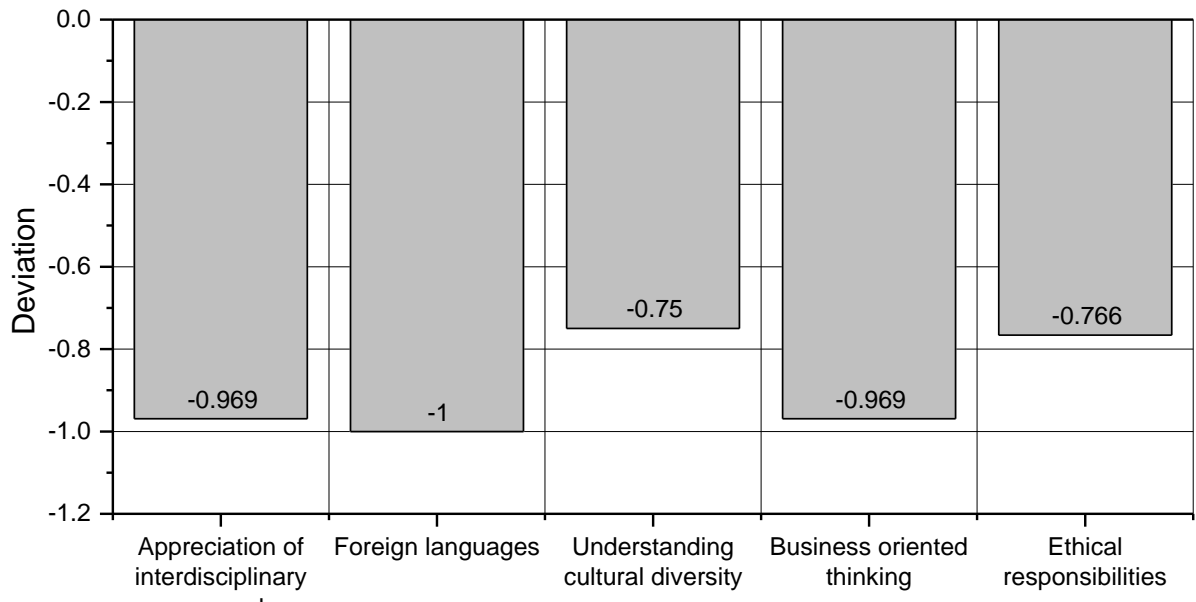

Figure 7 Full-time students' lowest rated skills in terms of perceived degree of learning $\left(\overline{\Delta_{s}}\right)$.

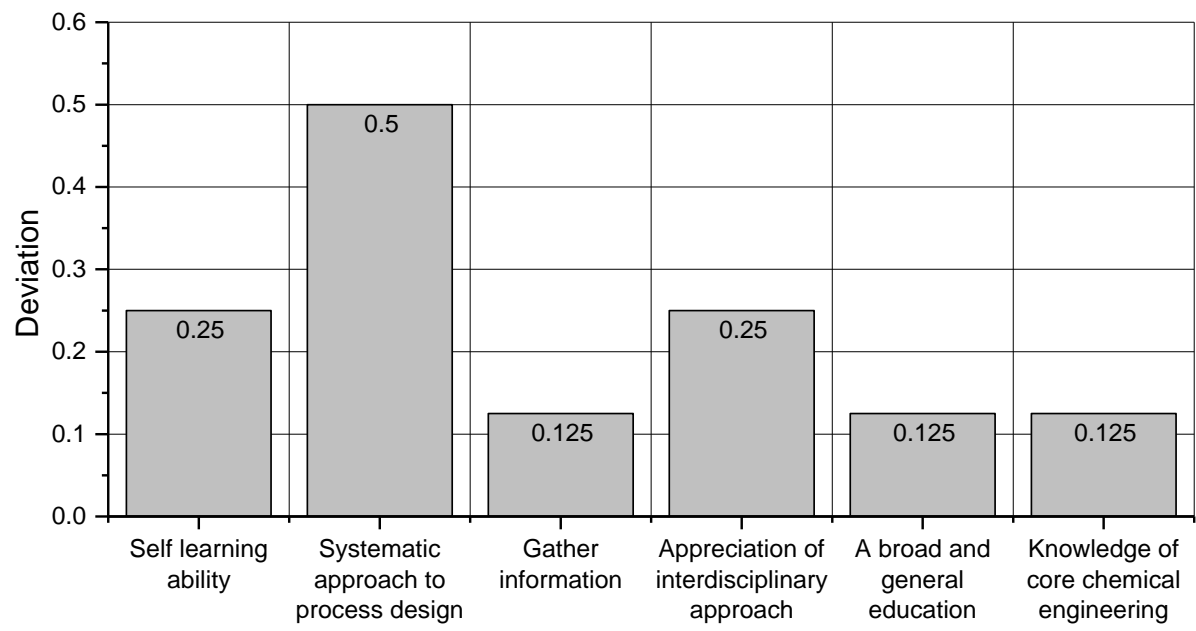

Figure 8 Part- students' highest perceived chemical engineering skills deviation $\left(\overline{\Delta_{S}}\right)$. 


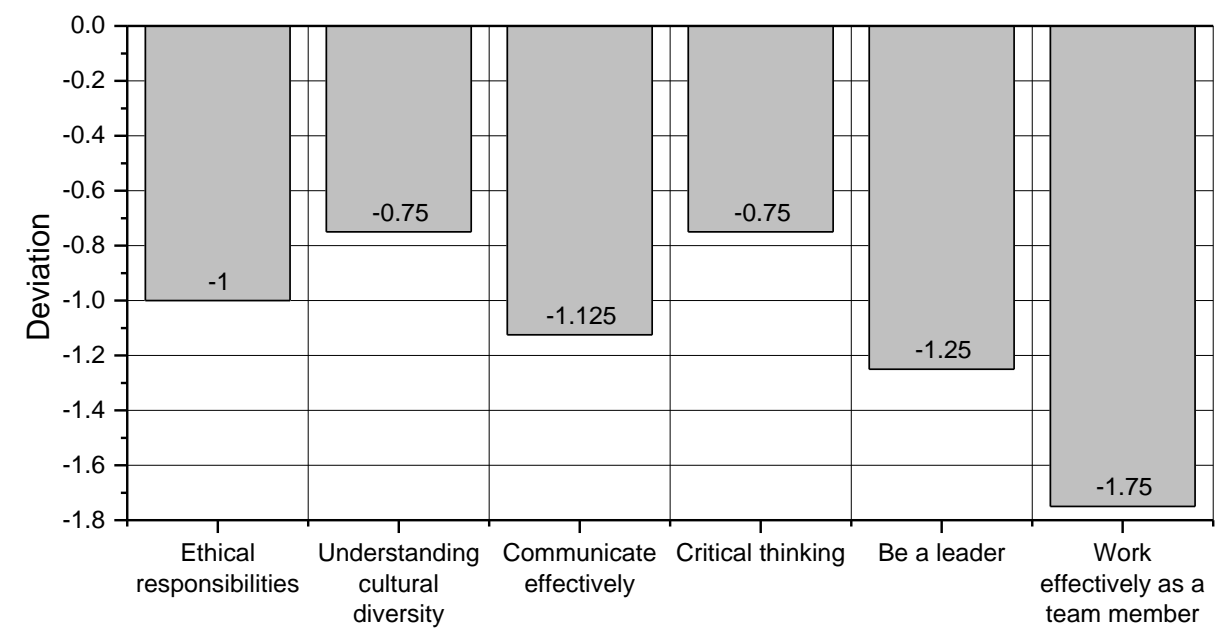

Figure 9 Part- students' lowest perceived chemical engineering skills deviation $\left(\overline{\Delta_{S}}\right)$.

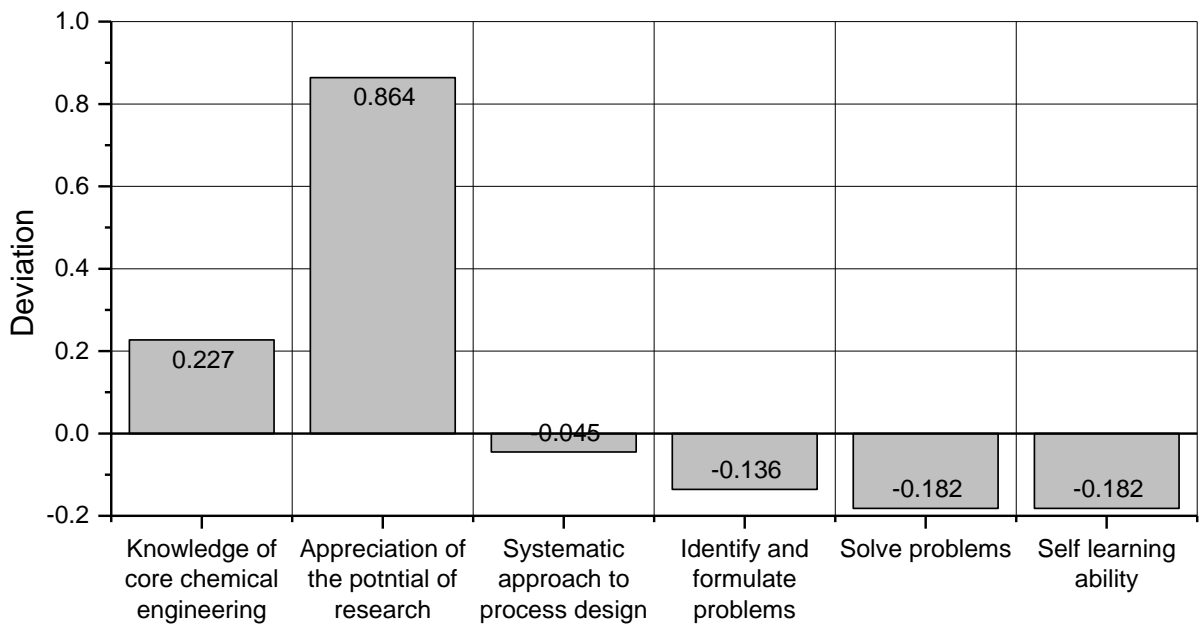

Figure 10 Alumni highest rated skills in terms of perceived degree of learning $\left(\overline{\Delta_{s}}\right)$.

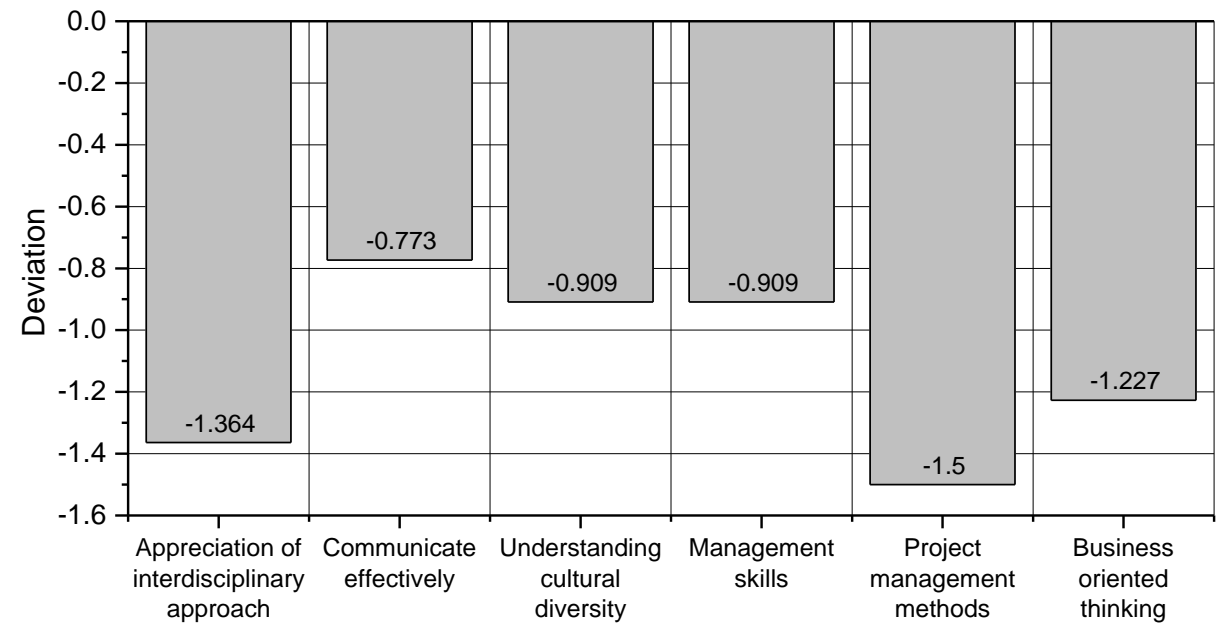

Figure 11 Alumni lowest rated skills in terms of perceived degree of learning $\left(\overline{\Delta_{s}}\right)$. 


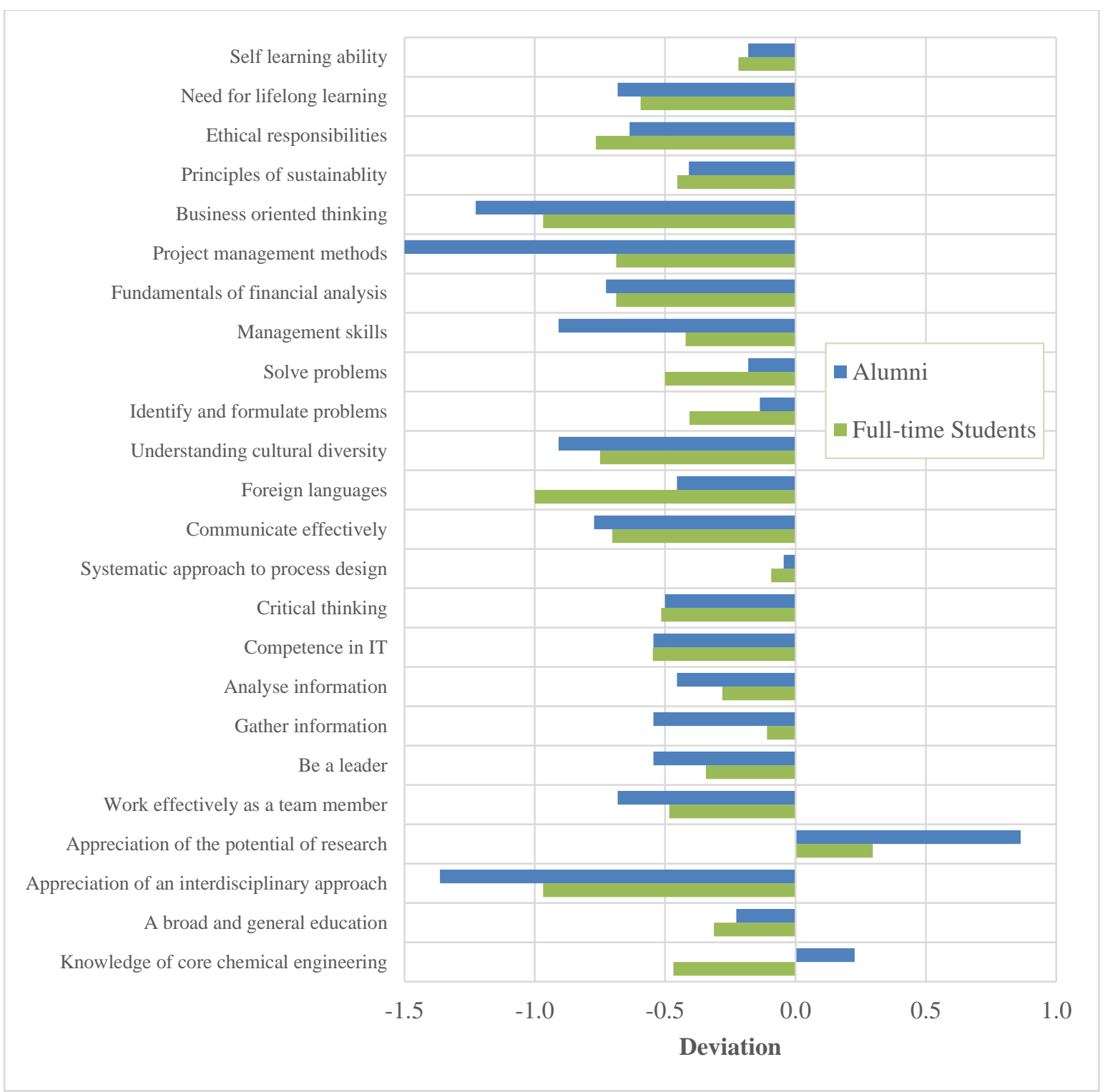

Figure 12 Chemical engineering skills' deviation $\left(\overline{\Delta_{s}}\right)$ comparison of full-time students and alumni 
Communicate effectively

Work effectively as a team member

Critical thinking

Analyse information

Gather information $\mathbf{X}$
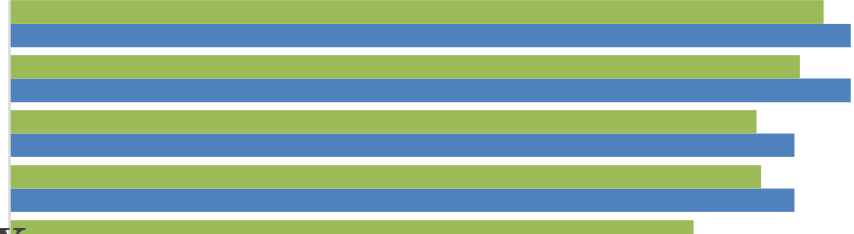

Appreciation of an interdisciplinary approach $\mathbf{X}$

Solve problems

Self learning ability

Project management methods $\mathbf{X}$

Identify and formulate problems

A broad and general education

Competence in IT

Business oriented thinking $\mathbf{X}$

Management skills

Be a leader

Knowledge of core chemical engineering $\mathbf{X}$

Need for lifelong learning

Systematic approach to process design

Ethical responsibilities $\mathbf{X}$

Fundamentals of financial analysis Principles of sustainablity $\mathbf{X}$

Understanding cultural diversity
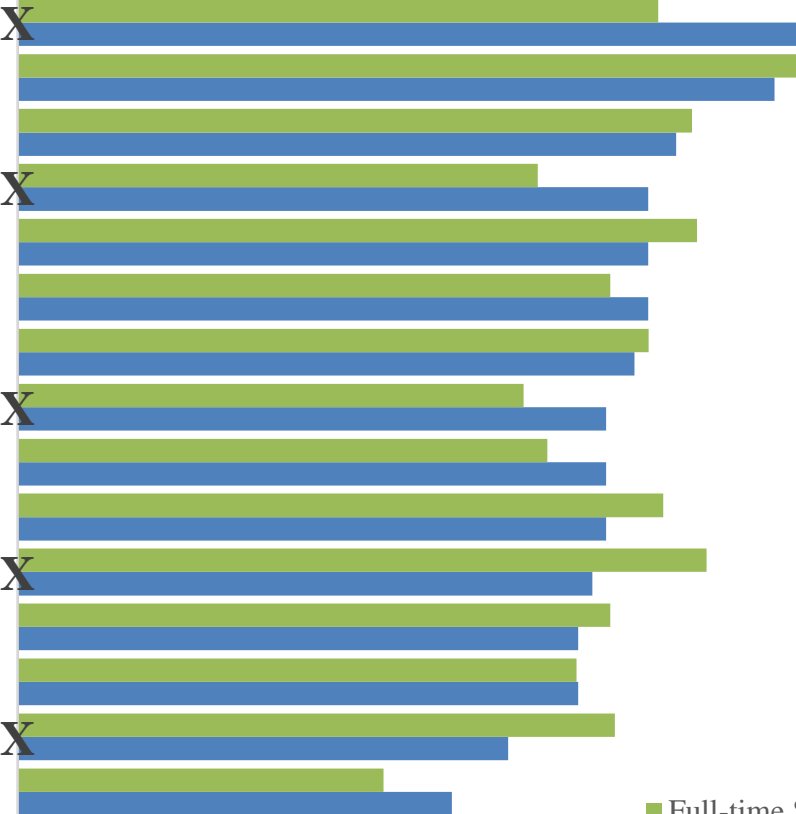

- Full-time Students

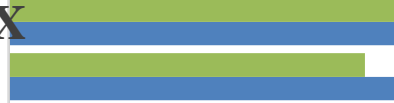

- Alumni

Appreciation of the potential of research $\mathbf{X}$

Foreign languages

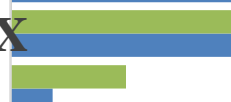

2

3

3.5

4

4.5

Average Response for Employment

Figure 13 Average response for employment importance - full-time students and alumni (ranked for alumni); skills considerably exceeding the average difference between the full-time students and alumni groups are highlighted with an ' $X$ '. 


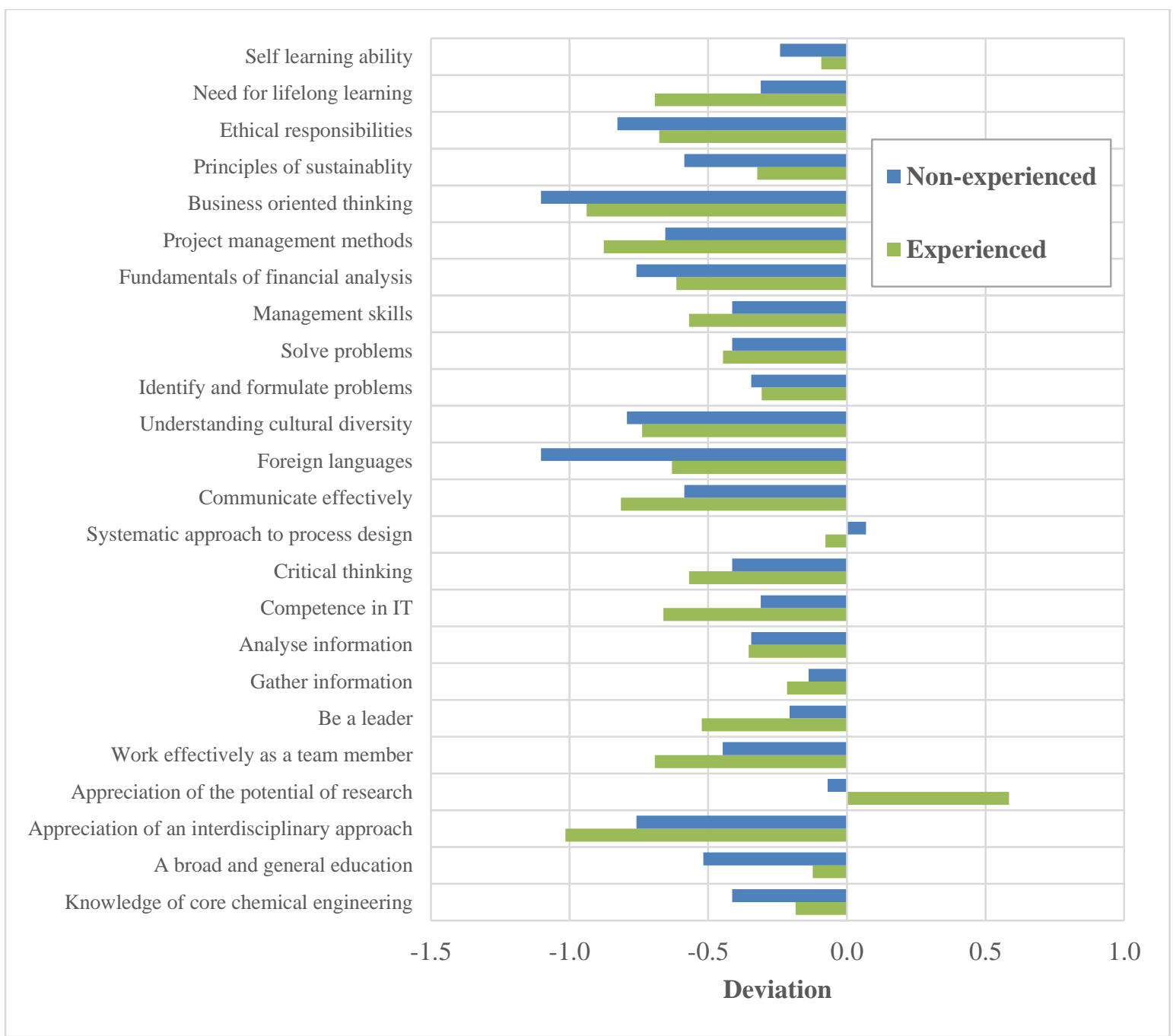

Figure 14 Skills' Deviation Comparison $\left(\overline{\Delta_{s}}\right)$ of Experienced and Non-experienced Participants 


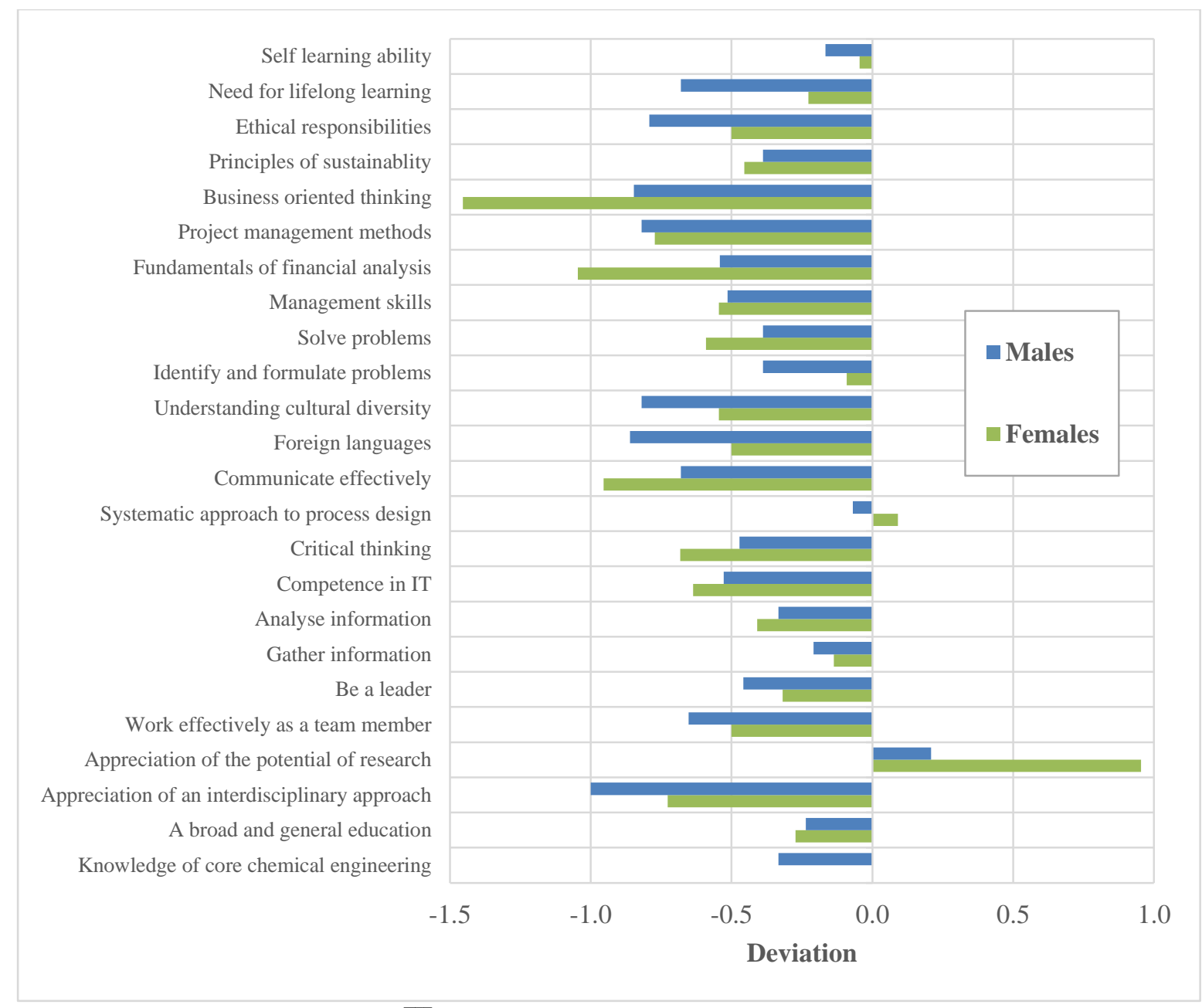

Figure 15 Skills' Deviation Comparison $\left(\overline{\Delta_{s}}\right)$ of Male and Female Participants for all cohorts (full-time, part-time and alumni). 
5

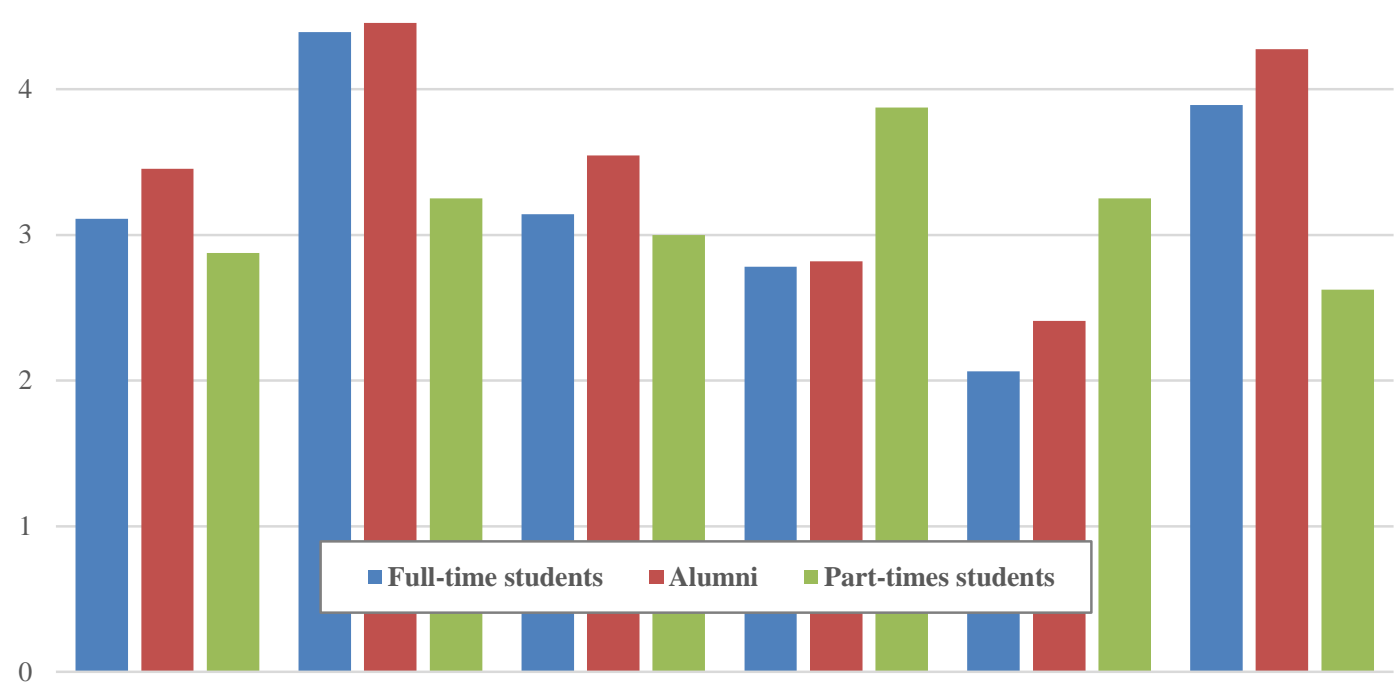

0 Traditional lectures
Traditional lectures with tutorial support

Figure 16 Teaching Method Preferences of Full-time Students, Part-time Students and Alumni 


\section{Tables}

Table 1 Comparison of similar LOs found in accreditation documentation of various accrediting bodies $[2,6,7]$

\begin{tabular}{|c|c|c|}
\hline $\begin{array}{l}\text { IChemE } \\
\text { Course Accreditation Guide }\end{array}$ & $\begin{array}{c}\text { ABET } \\
\text { Engineering Criteria } 2000\end{array}$ & $\begin{array}{c}\text { EA } \\
\text { Policy on Accreditation of } \\
\text { Professional Engineering Programs }\end{array}$ \\
\hline $\begin{array}{l}\text { - Knowledge and understanding: } \\
\text { essential facts, concept, theories } \\
\text { and principles of chemical } \\
\text { engineering and its underpinning } \\
\text { mathematics and sciences. } \\
\text { - Intellectual abilities: application } \\
\text { of appropriate quantitative } \\
\text { science and engineering tools to } \\
\text { the analysis of problems. } \\
\text { - Practical skills: acquired through } \\
\text { laboratory, individual and group } \\
\text { project work. } \\
\text { - General transferable skills: } \\
\text { communication, time } \\
\text { management, team working, } \\
\text { inter-personal skills, effective use } \\
\text { of IT. }\end{array}$ & $\begin{array}{l}\text { - Ability to apply knowledge of } \\
\text { mathematics, science, and } \\
\text { engineering } \\
\text { - Ability to use the techniques, } \\
\text { skills and modern engineering } \\
\text { tools necessary for engineering } \\
\text { practice. Ability to identify, } \\
\text { formulate, and solve } \\
\text { engineering problems } \\
\text { - Ability to design and conduct } \\
\text { experiments, as well as to } \\
\text { analyze and interpret data } \\
\text { - Ability to communicate } \\
\text { effectively. Ability to function on } \\
\text { multi-disciplinary teams. An } \\
\text { understanding of professional } \\
\text { and ethical responsibility. }\end{array}$ & $\begin{array}{l}\text { - Ability to apply knowledge of } \\
\text { basic science and engineering } \\
\text { fundamentals } \\
\text { - Ability to undertake problem } \\
\text { identification, formulation and } \\
\text { solution. } \\
\text { - In-depth technical competence in } \\
\text { at least one engineering discipline } \\
\text { - Ability to communicate effectively; } \\
\text { creativity and innovation; function } \\
\text { effectively as individual, team } \\
\text { leader and member in multi- } \\
\text { disciplinary teams, understanding } \\
\text { of professional and ethical } \\
\text { responsibilities. }\end{array}$ \\
\hline
\end{tabular}


Table 2 Confederation British Industry (CBI) employability skills definitions and employer dissatisfaction percentage by year (data compiled from [8-10])

\begin{tabular}{|c|c|c|c|c|}
\hline \multirow{2}{*}{ Employability skill } & \multirow{2}{*}{ Definition } & \multicolumn{3}{|c|}{ \% Dissatisfied } \\
\hline & & 2011 & 2012 & 2013 \\
\hline $\begin{array}{l}\text { Business and } \\
\text { customer awareness }\end{array}$ & $\begin{array}{l}\text { Basic understanding of the key drivers for businesses success } \\
\text { and the need to provide customer satisfaction }\end{array}$ & 44 & 47 & 48 \\
\hline Self-management & $\begin{array}{l}\text { Readiness to accept responsibility, flexibility, time } \\
\text { management, readiness to improve own performance }\end{array}$ & 25 & 31 & 32 \\
\hline Team working & $\begin{array}{l}\text { Respecting others, co-operating, negotiating/persuading, } \\
\text { contributing to discussions }\end{array}$ & 20 & 25 & 19 \\
\hline Problem solving & $\begin{array}{l}\text { Analysing facts and circumstances and applying creative } \\
\text { thinking to develop appropriate solutions }\end{array}$ & 19 & 23 & 27 \\
\hline $\begin{array}{l}\text { Communication and } \\
\text { literacy }\end{array}$ & $\begin{array}{l}\text { Application of literacy, ability to produce clear written work and } \\
\text { oral literacy, including listening and questioning }\end{array}$ & 17 & 15 & 20 \\
\hline $\begin{array}{l}\text { Application of } \\
\text { numeracy }\end{array}$ & $\begin{array}{l}\text { Manipulation of numbers, general mathematical awareness } \\
\text { and its application in practical contexts }\end{array}$ & 9 & 10 & 15 \\
\hline Application of IT & $\begin{array}{l}\text { Basic IT skills including familiarity with word processing, } \\
\text { spreadsheets, file management and use of internet search } \\
\text { engines }\end{array}$ & 5 & 6 & 3 \\
\hline
\end{tabular}


Table 3 World Chemical Engineering Council generic skills results ranked in order of importance to work (data compiled from [11])

\begin{tabular}{|c|c|c|c|c|c|}
\hline \multirow{2}{*}{$\begin{array}{l}\text { Rank wrt } \\
\text { work }\end{array}$} & \multirow{2}{*}{ Generic skill/ability } & \multicolumn{2}{|c|}{ Average response } & \multirow{2}{*}{$\begin{array}{c}\text { Deviation }\left(\overline{\Delta_{s}}\right) \\
{\left[\left(\overline{x_{e}}\right)-\left(\overline{x_{w}}\right)\right]}\end{array}$} & \multirow{2}{*}{$\begin{array}{l}\text { Rank wrt } \\
\text { deviation }\end{array}$} \\
\hline & & Work $\left(\overline{x_{w}}\right)$ & Education $\left(\overline{x_{e}}\right)$ & & \\
\hline 1 & Ability to work effectively as a member of a team & 4.364 & 3.850 & -0.514 & 13 \\
\hline 2 & Ability to analyse information & 4.323 & 4.053 & -0.270 & 20 \\
\hline 3 & Ability to communicate effectively & 4.279 & 3.482 & -0.797 & 5 \\
\hline 4 & Ability to gather information & 4.232 & 3.966 & -0.266 & 21 \\
\hline 5 & Self-learning ability & 4.232 & 3.937 & -0.295 & 19 \\
\hline 6 & Ability to solve problems & 4.222 & 3.884 & -0.338 & 18 \\
\hline 7 & Appreciation of an interdisciplinary approach & 4.028 & 3.524 & -0.504 & 14 \\
\hline 8 & Critical thinking & 3.978 & 3.578 & -0.400 & 16 \\
\hline 9 & Ability to identify and formulate problems & 3.972 & 3.564 & -0.408 & 15 \\
\hline 10 & Importance of a broad and general education & 3.958 & 3.803 & -0.155 & 24 \\
\hline 11 & Expectation of the need for life-long learning & 3.950 & 3.433 & -0.517 & 12 \\
\hline 12 & Understanding of ethical and professional responsibilities & 3.924 & 3.208 & -0.716 & 7 \\
\hline 13 & Ability to be a leader & 3.834 & 3.155 & -0.679 & 8 \\
\hline 14 & Ability to apply knowledge of basic science and chemical engineering fundamentals & 3.754 & 4.063 & +0.309 & 25 \\
\hline 15 & Management skills & 3.696 & 2.726 & -0.970 & 2 \\
\hline 16 & Ability to use a systematic approach to process and product design & 3.614 & 3.367 & -0.247 & 23 \\
\hline 17 & Competence in information technology & 3.596 & 3.339 & -0.257 & 22 \\
\hline 18 & Knowledge of methods for project management & 3.365 & 2.401 & -0.964 & 3 \\
\hline 19 & Understanding of cultural diversity & 3.332 & 2.812 & -0.520 & 11 \\
\hline 20 & Business orientated thinking/business approach & 3.332 & 2.275 & -1.057 & 1 \\
\hline 21 & Appreciation of the potential of research & 3.242 & 3.576 & +0.334 & 26 \\
\hline 22 & Understanding of principles of sustainable development & 3.196 & 2.671 & -0.525 & 10 \\
\hline 23 & Understanding of fundamental principles of financial analysis & 3.141 & 2.604 & -0.537 & 9 \\
\hline 24 & Knowledge of methods for total quality management & 3.063 & 2.186 & -0.877 & 4 \\
\hline 25 & Foreign languages & 2.887 & 2.488 & -0.399 & 17 \\
\hline 26 & Knowledge of marketing principles & 2.730 & 1.998 & -0.732 & 6 \\
\hline
\end{tabular}

